\title{
Anesthesia Management of a Case of a Huge Ranula: A Case Report
}

\author{
Pallavi A Kharat ${ }^{1}$, Hema C Solanki ${ }^{2}$, Sunil K Gvalani ${ }^{3}$, Harprit K Madan ${ }^{4}$, Latika S Kumar Singh ${ }^{5}$
}

\begin{abstract}
Ranulas are mucous retention cysts arising out of submandibular and sublingual salivary glands. ${ }^{1}$ They usually occupy the floor of the mouth, lifting the tongue upward, and causing potential airway obstruction. They turn out to be a challenge for airway management for anesthesiologists. A 43-year-old male patient presented with a recurrent swelling in the floor of the mouth pushing the tongue upward and to the left side and completely obstructing the view of the posterior pharyngeal wall. He was operated on for the same swelling 2 years ago and had a recurrence for the last 8 months. He was planned for complete excision of the swelling under general anesthesia. We present a case report of successful management of difficult airway by using awake fiberoptic intubation of a patient posted for excision of large plunging ranula under general anesthesia.

Keywords: Difficult airway, Fiberoptic intubation, Plunging ranula.

Research and Innovations in Anesthesia (2020): 10.5005/jp-journals-10049-0086
\end{abstract}

\section{INTRODUCTION}

Ranulas are retention cysts arising from the submandibular and sublingual salivary glands found in the floor of the mouth. The exact prevalence of plunging ranula is not known but these lesions are considered uncommon. Those extending into the neck are called plunging ranula. As they arise from the floor of the mouth and lift the tongue upward, they pose a challenge for airway management. There are different approaches to secure a difficult airway in such a case and we should always be ready with a definite plan along with an alternative. So, we report a case of difficult airway management in a patient having a large plunging ranula posted for excision under general anesthesia.

\section{Case Description}

A 43-year-old man, $50 \mathrm{~kg}$ by weight came with a history of recurrent swelling in the intraoral cavity extending in the neck for the last 8 months. The swelling was initially pea-sized which gradually increased to the size of a lemon. It was around $4 \times 5 \mathrm{~cm}$ in submental region (Fig. 1A) and $3 \times 4 \mathrm{~cm}$ intraorally (Fig. 1B). The intraoral part of the swelling was pushing the tongue upward and toward the left obliterating the view of the uvula and soft palate (Mallampatti grade IV) (Fig. 1B). It was compressible and not associated with pain. There was no difficulty in swallowing either liquids or solid food and no difficulty in breathing. The contrast enhanced computed tomography neck was suggestive of recurrent large cystic lesion of $8.6 \times 4.5 \times 4.1 \mathrm{~cm}$ arising from sublingual space extending into the submandibular space (Fig. 2). On preanesthetic evaluation, his mouth opening was three fingers, Mallampatti grade IV and with normal thyromental distance. All routine investigations were within normal limits.

The excision of plunging ranula was planned under general anesthesia and awake fiberoptic intubation was our plan for airway management. A difficult airway cart was kept ready. The patient was explained and reassured about the procedure and informed consent was taken. He was nebulized with $4 \%$ topical lignocaine for 10 minutes before the procedure. Xylometazoline drops were instilled in both the nostrils for decongestion. All
${ }^{1-4}$ Department of Anaestheisa, HinduHridaySamrat Balasaheb Thackeray Medical College and Dr Rustom Narsi Cooper Municipal General Hospital, Mumbai, Maharashtra, India

${ }^{5}$ Department of Anesthesiology, HinduHridaySamrat Balasaheb Thackeray Medical College and Dr Rustom Narsi Cooper Municipal General Hospital, Mumbai, Maharashtra, India

Corresponding Author: Pallavi A Kharat, Department of Anaestheisa, HinduHridaySamrat Balasaheb Thackeray Medical College and Dr Rustom Narsi Cooper Municipal General Hospital, Mumbai, Maharashtra, India, Phone:+91 9819689428,e-mail:pallavisomkuwar@ gmail.com

How to cite this article: Kharat PA, Solanki HC, Gvalani SK, et al. Anesthesia Management of a Case of a Huge Ranula: A Case Report. Res Inno in Anesth 2020;5(2):46-48.

Source of support: Nil

Conflict of interest: None

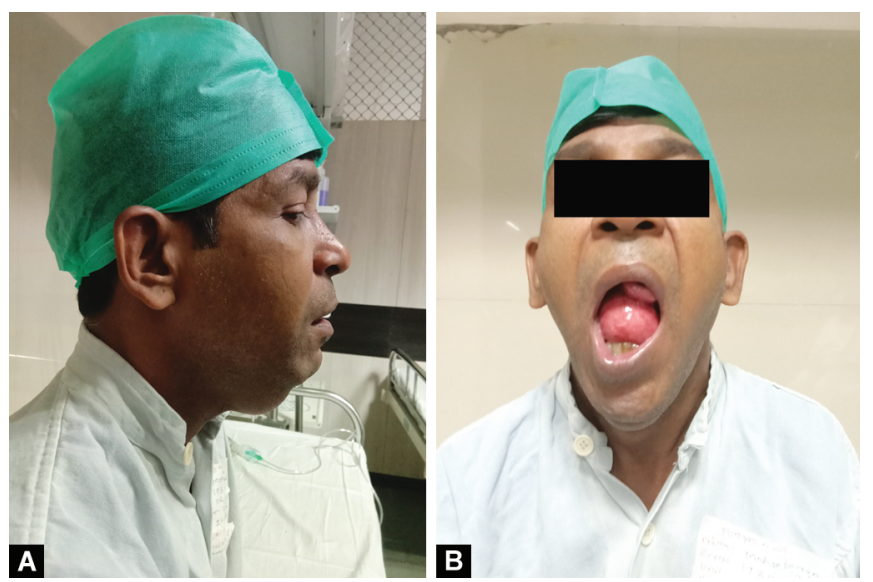

Figs $1 \mathrm{~A}$ and B: Lateral and anterior view of ranula. A swelling in submandibular region seen on lateral view. Intraoral swelling seen on anterior view

American Society of Anesthesiologists (ASA) standard monitors like

(c) The Author(s). 2020 Open Access This article is distributed under the terms of the Creative Commons Attribution 4.0 International License (https:// creativecommons.org/licenses/by-nc/4.0/), which permits unrestricted use, distribution, and non-commercial reproduction in any medium, provided you give appropriate credit to the original author(s) and the source, provide a link to the Creative Commons license, and indicate if changes were made. The Creative Commons Public Domain Dedication waiver (http://creativecommons.org/publicdomain/zero/1.0/) applies to the data made available in this article, unless otherwise stated. 


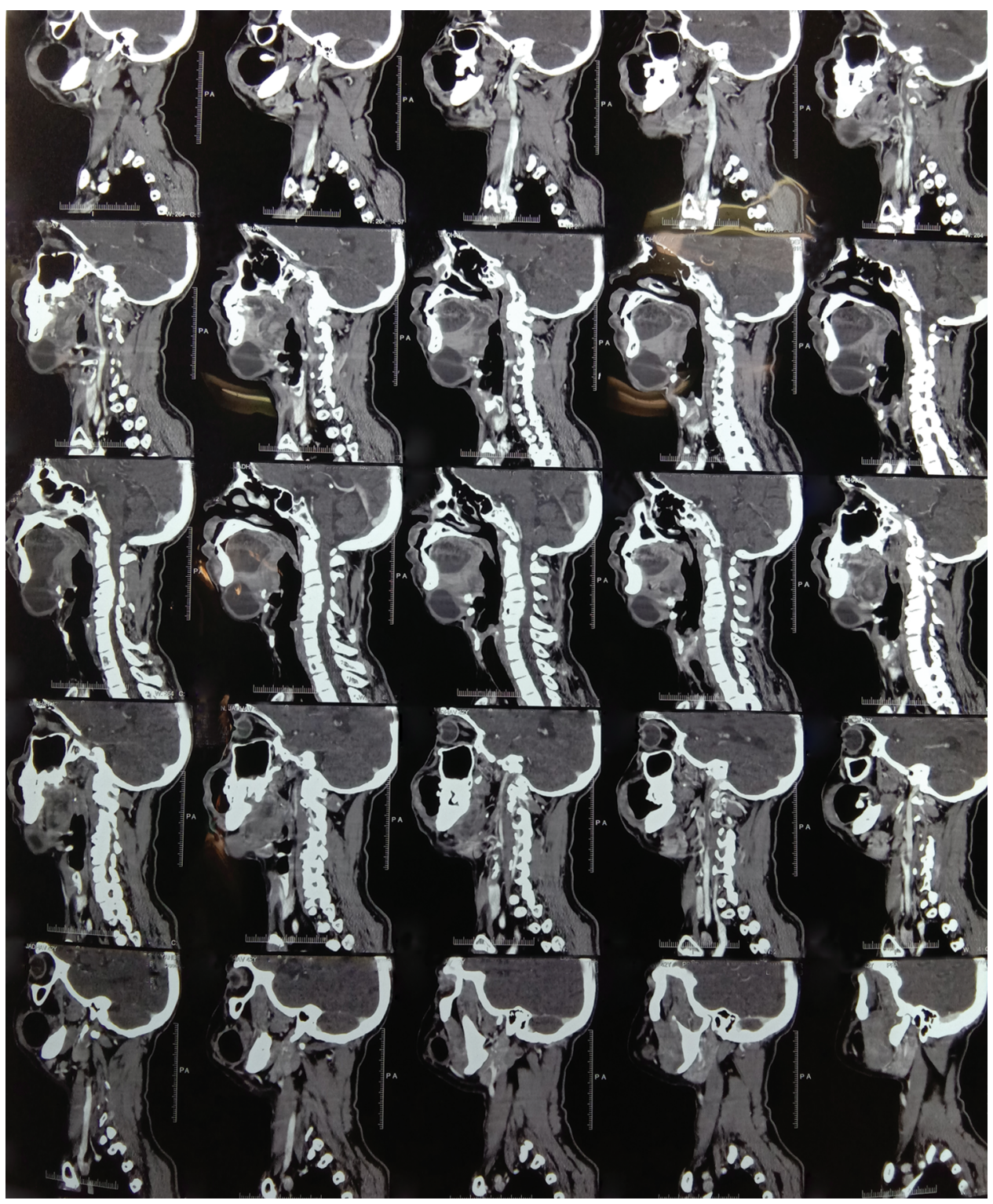

Fig. 2: Contrast-enhanced computed tomography (CECT) showing the ranula

electrocardiogram (ECG), non invasive blood pressure (NIBP), and oxygen saturation $\left(\mathrm{SpO}_{2}\right)$ were attached to the patients. Oxygen was given at $3 \mathrm{~L} /$ minute by nasal prongs. Inj. glycopyrrolate 0.2 mg, Inj. midazolam $1 \mathrm{mg} \mathrm{i} / \mathrm{v}$, and Inj. fentanyl $100 \mu \mathrm{g}$ i/v were given as premedication. Bilateral superior laryngeal nerve blocks (1.5 mL of $2 \%$ lignocaine) and transtracheal nerve blocks ( $3 \mathrm{~mL}$ $2 \%$ lignocaine) were given. Inj. dexmedetomidine infusion was given in a loading dose of $1 \mu \mathrm{g} / \mathrm{kg}$ for awake fiberoptic intubation. A 6.5-mm flexometallic cuffed endotracheal tube was railroaded after the fiberoptic scope was passed beyond the vocal cords and carina was visualized. The cuff was inflated and correct tube placement was confirmed by capnography and bilateral equal air entry. Inj. propofol $2 \mathrm{mg} / \mathrm{kg}$ and Inj. vecuronium $0.1 \mathrm{mg} / \mathrm{kg}$ were given thereafter. Throat packing was done after tube fixation. The anesthesia was maintained with oxygen, nitrous oxide 50:50, sevoflurane $0-2 \%$, and boluses of Inj. vecuronium. The swelling was excised by a submental approach (Fig. 3). A swelling of about $8.5 \times 5 \mathrm{~cm}$ was excised. Intraoperatively, inj. dexamethasone $8 \mathrm{mg}$,

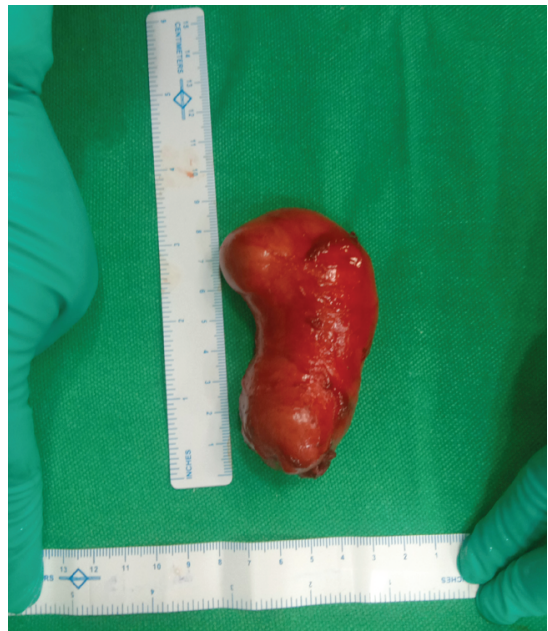

Fig. 3: Excised ranula 
inj. hydrocortisone $100 \mathrm{mg}$, and inj. ondansetron $4 \mathrm{mg}$ were given $\mathrm{i} / \mathrm{v}$. Inj. paracetamol $1 \mathrm{~g}$ and inj. diclofenac $50 \mathrm{mg}$ was given i/v for postoperative analgesia. The patient was hemodynamically stable throughout the procedure and was extubated uneventfully. Postoperatively, the patient was stable and observed in anesthesia intensive care unit (ICU) and shifted to the ward on the second postoperative day.

\section{Discussion}

A plunging ranula is a pseudocyst caused by extravasation of mucous from obstruction of the sublingual and submandibular salivary gland. ${ }^{2}$ It presents as either a midline or lateral swelling in the neck and has an intraoral extension. Intraoral swelling makes the airway difficult and hence need to have a proper strategy for airway management. They encroach and occupy the oral cavity making glottic visualization and maneuvering endotracheal tube difficult. ${ }^{3}$ Awake fiberoptic intubation is the standard approach for the management of such difficult airways. But various methods like awake blind nasal intubation and retrograde intubation can be used where fiberoptic bronchoscope is not available. If a fiberoptic bronchoscope is not available then inhalational induction is preferred. The patient is taken into a deeper plane, direct laryngoscopy is done, and Inj. succinylcholine is given only after visualization of the glottic opening. Besides this, blind nasal intubation can be used in patients breathing spontaneously under deep inhalational anesthesia or it can be done as an awake blind nasal intubation under topical anesthesia. ${ }^{4}$

Retrograde intubation is an age-old technique for managing such difficult airways. We selected awake fiberoptic intubation for this case as it is the gold standard for managing the difficult airway. As most of the difficult airway conditions can be easily approached and managed effectively with the availability of a fiberoptic bronchoscope. Under upper airway blocks, the use of awake fiberoptic intubations is well established and superior to conventional laryngoscopy. Although the safest choice of securing the airway sometimes it is difficult to visualize the larynx due to the presence of secretions or blood.

In our case, huge intraoral swelling made the conventional laryngoscopy difficult so we planned awake fiberoptic intubation as an initial plan for establishing airway as it was available in our institution.

\section{Conclusion}

We conclude that a difficult airway should always be managed by having a planned strategy to avoid any catastrophic situations. Awake fiberoptic intubation is the gold standard for managing a difficult airway.

\section{References}

1. Sethi SK, Jain N, Khare A, et al. Anaesthetic management in a case of large plunging ranula with difficult airway: a case report. Egypt J Anaesthe 2017;33(2):209-212. DOI: 10.1016/j.egja.2016.09.002.

2. Dhingra PL, Dhingra S. Chapter 77 Neck Masses. Diseases of Ear, Neck and Throat and Head and Neck Surgery. 6th ed., Reed Elsevier, India Private Limited; 2014. p. 392.

3. Bindra A, Kumar N, Yadav N, et al. Anaesthetic concerns in a huge congenital sublingual swelling obscuring airway access. Saudi J Anaesth 2015;9(2):202-203. DOI: 10.4103/1658-354X.152888.

4. Swaika S, Sheet J, Mandal A, et al. Anaesthesia management in a case of huge plunging ranula. Anaesthe, Essays Res 2014;8(1):114-116. DOI: 10.4103/0259-1162.128929. 